\title{
Research on Simplified Calculation Method of Coupled Vibration of Vehicle-Bridge System
}

\author{
Zenong Cheng $\mathbb{D}^{1},{ }^{1}$ Nan Zhang $\mathbb{D}^{1},{ }^{1}$ Qikai Sun $\left(\mathbb{D},{ }^{1}\right.$ Zeguo Shen $\mathbb{D D}^{2}$ and Xiao Liu ${ }^{1}{ }^{1}$ \\ ${ }^{1}$ School of Civil Engineering, Beijing Jiaotong University, Beijing 100044, China \\ ${ }^{2}$ Taiyuan Municipal Engineering Design and Research Institute, Taiyuan 030000, China
}

Correspondence should be addressed to Nan Zhang; nzhang@bjtu.edu.cn

Received 11 March 2021; Accepted 5 May 2021; Published 19 May 2021

Academic Editor: Giuseppe Ruta

Copyright $(92021$ Zenong Cheng et al. This is an open access article distributed under the Creative Commons Attribution License, which permits unrestricted use, distribution, and reproduction in any medium, provided the original work is properly cited.

A modified moving loads' model is proposed for the vehicle-bridge coupling vibration simulation. Taking the vehicle-bridge interaction model (VBI) as the reference, the accuracy and applicability of the three calculation models, namely, moving loads' model, moving mass model, and spring-damper-mass model, are compared using the frequently-used railway simply-supported beam with a span of 32 meters as the research object. Influencing factors such as vehicle speed, mass ratio of vehicle and beam, and primary spring stiffness on the dynamic response of the vehicle-bridge system are discussed in detail. The results show that the moving load model has the best performance on the stability of the deviation rate, but its calculation results are smaller than the other two methods as well as the VBI. The values of the deviation rate for the moving mass model and the spring-damper-mass model are large, and the stability of those are insufficient in the range of $80 \% \sim 120 \%$ of the first resonance velocity. Except for that, the results of the two models are in good agreement with the VBI model. According to above analysis, a modified moving loads' model with two amplification coefficients, namely, 1.10 for the range of $90 \% \sim 105 \%$ of the first resonance velocity and 1.05 for other velocities, are proposed, which has higher calculation efficiency and accuracy.

\section{Introduction}

Since 1997, China's trains have increased their speeds six times [1], from the "Green Railway Carriage" era 20 years ago, to the "Red Railway Carriage" 15 years ago, and then to the "China Railway High-Speed (CRH)" in 2007, and even the "China Rejuvenation (CR)" in recent years; the operating speed has increased from the top speed of $140 \mathrm{~km} / \mathrm{h}$ to the current $350 \mathrm{~km} / \mathrm{h}$, and the speed will develop to $400 \mathrm{~km} / \mathrm{h}$ in the future [2], and it is constantly being refreshed. With the continuous improvement of train speed, the dynamic problem between the high-speed train and railway bridge is becoming increasingly prominent, and the coupling vibration between the train and bridge is becoming more and more serious [3-5].

The vehicle-bridge coupled vibration analysis model has undergone the following stages of development.

In the initial stage, Willis ignored the mass of the bridge in a report on bridge vibration and simplified the train load to moving concentration; Timoshenko [6] considered the bridge quality, simplified the train load to moving concentrated force, and established the bridge vibration equation that only considered the vertical direction; Inglis [7] and Kolousek [8] regarded the train load as a single-moving periodic force and considered the mass of the bridge and the vehicle to analyze the problem of single wheel crossing the bridge. Li and Zhang [9] obtained the moving load velocities which led to the extreme responses of bridge free vibration under single-moving constant force or harmonic force and put forward the corresponding formula by analyzing the moving load spectrum in detail. Nowadays, a large number of scholars use this method to analyze the dynamics of bridges [10-17], and Europe [18] wrote this model into specifications to guide the bridge design.

In order to consider the influence of the train mass on the vibration of the vehicle bridge, Yang and Yau $[19,20]$ simplified the vehicle into a suspended mass, distributed the mass to the car body and the bogie, established a bridge 
model using the finite element method, and analyzed the dynamic response of the bridge; Chen et al. [21, 22] studied the dynamic response of the beam under the action of the moving mass and deduced its vibration equation.

Because there are springs and damping in the vehicle system, scholars [23-25] presented a semianalytical solution to the problem of a simple supported beam subjected to a moving sprung mass with initial velocity and constant acceleration or deceleration.

In order to make the model closer to the actual vehicle, Dhar established the vehicle as a multirigid body system composed of spring connecting parts between the car body, bogie, and wheelset. The wheel-rail interaction was considered as the excitation source of the vehicle-bridge system, and the vertical vibration of the vehicle-bridge system was analyzed. Chinese scholars Gao et al. $[26,27]$ considered the 31 DOF vehicle model; Zhang et al. [28-32] established the 27 DOF space vehicle model, and all of them conducted a lot of research on vehicle-bridge interaction.

In the above literature, the relevant analysis of each model has been carried out, but the detailed comparative analysis of three simplified calculation methods such as moving load model, moving mass model, and springdamping-mass model has not been carried out, and the applicability of different models has not been pointed out. Because the dynamic coefficient is an important indicator of the bridge design, this paper discusses the advantages and disadvantages of the three simplified calculation methods in detail based on the deviation rate of the dynamic coefficient under consideration of different vehicle-bridge mass ratios. A simple and practical simplified calculation model of vehicle-bridge coupling is obtained, which provides a basis for rational selection of the vehicle-bridge coupling calculation model in future engineering applications. Compared with UIC776-2 [18] specification, "in dynamic calculation, the train is represented by axle load and spacing and passes through the bridge at a constant speed. This model is sufficient for dynamic calculation." It is recommended that similar regulations be added to the Chinese code.

\section{Simplification Method of the Vehicle-Bridge Coupling Model}

In the research process of the interaction of the vehicle and bridge problem, the vibration theory of vehicle-bridge coupling is constantly improving, and its analysis model and calculation method have also undergone changes from simple to complex. The explanation of these four models is as follows.

2.1. The Moving Load Model. The common $32 \mathrm{~m}$ simple supported box girder has a mass of more than 1,100 tons, while the mass loaded on the single-span simple supported beam when the train passes through the bridge is about 60 tons. It can be seen that the loading mass of the train is far less than that of the simple supported beam. The common $32 \mathrm{~m}$ simple-supported box girder has a mass of more than 1,100 tons, while the mass of the single-span simple supported girder loaded by the train passing through the bridge is about 60 tons. Therefore, this simplified model does not consider the inertial force generated by the mass when the train passes through the bridge, and with reference to UIC 776-2 specification, the vehicle is simplified as the moving load model [18], as shown in Figure 1.

Assuming that the mass of the simply supported beam is uniformly distributed and has a constant cross section, the span is $L$, the mass per unit beam length is $\bar{m}$, the stiffness is $E I$, and viscous damping whose damping force is proportional to the structural vibration speed is adopted. The parameters are the full length of single vehicle $L_{\mathrm{V}}$, distance between bogie centres $L_{C}$, and the fixed wheelbase of the wheelset $L_{\mathrm{W}}$.

The number is $P_{k j}\left(k=1,2,3, \ldots, N_{\mathrm{v}}\right.$ and $j=1,2,3$, and 4$)$ according to the forward direction of the train. The subscript $k$ represents the number of cars in which the wheelset is located, and $\mathrm{j}$ represents the location of the wheelset in the car. There is a time difference between the groups of concentrated forces. The time $t_{k j}$ for the $k$ th moving concentrated load of the $j$ th group to enter the bridge is still $t_{k}=k-1 L_{\mathrm{V}} / V$.

Applying the above model, the differential motion equation of a simply supported beam bridge is expressed as follows [16-23]:

$$
E I \frac{\partial^{4} y(x, t)}{\partial x^{4}}+\bar{m} \frac{\partial^{2} y(x, t)}{\partial t^{2}}+c \frac{\partial y(x, t)}{\partial t}=\sum_{k=1}^{N_{v}} \sum_{j=1}^{4} P \delta\left[x-V\left(t-t_{k j}\right)\right] .
$$

The expression of its generalized coordinates is

$$
\ddot{q}_{n}(t)+2 \xi_{n} \dot{q}_{n}(t)+\omega_{n}^{2} q_{n}(t)=\frac{2}{\bar{m} L_{b}} P \sum_{k=1}^{N_{v}} \sum_{j=1}^{4} \sin \frac{n \pi V}{L_{b}}\left[x-V\left(t-t_{k j}\right)\right] .
$$



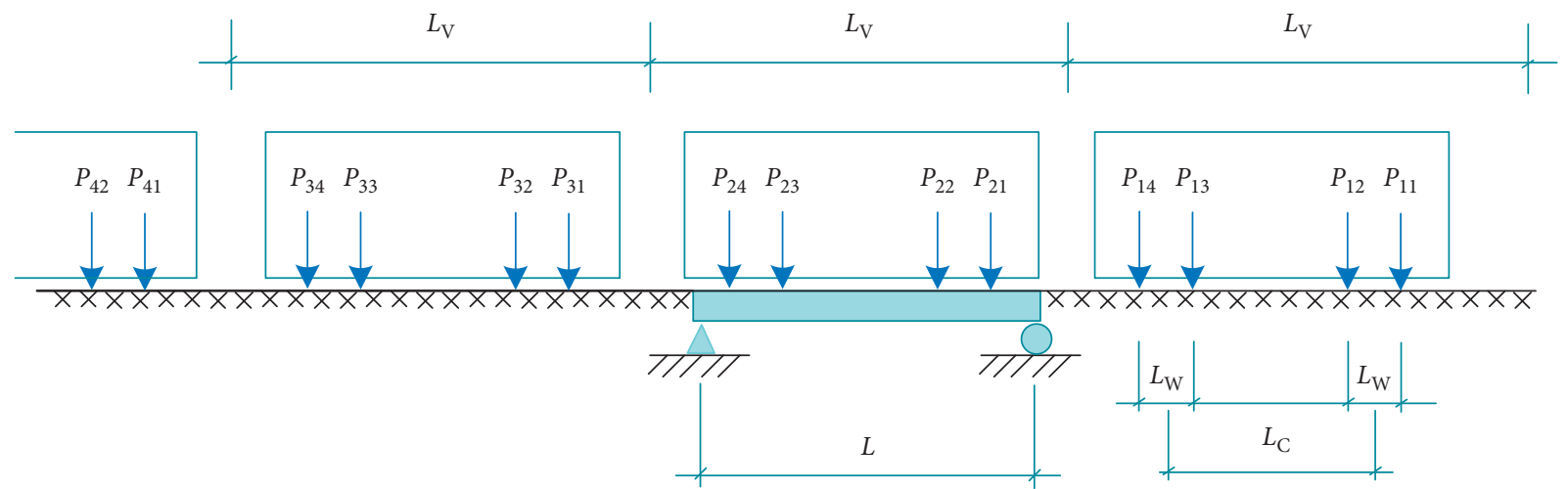

Figure 1: The moving load model.

Correspondingly, the analytical solution of the vertical vibration displacement of a simply supported bridge considering only the first mode of vibration is

$$
\begin{aligned}
y(x, t)= & \sin \frac{N \pi x}{L_{b}} \sum_{k=1}^{N_{v}} \sum_{j=1}^{4} e^{-\xi \omega\left(t-t_{k j}\right)}\left[A \sin \omega_{D}(t)+B \cos \omega_{D}(t)\right] \\
& +\left(\frac{2 P L^{3}}{E I \pi^{4}}\right) \frac{1}{\left(1-\beta^{2}\right)^{2}+(2 \xi \beta)^{2}} \sin \frac{\pi x}{L} \sum_{k=1}^{N_{v}} \sum_{j=1}^{4}\left[\left(1-\beta^{2}\right) \sin \bar{\omega}(t)-2 \xi \beta \cos \bar{\omega}(t)\right],
\end{aligned}
$$

where $\omega=(\pi / L)^{2} \sqrt{E I / \bar{m}}$ is the natural circular frequency of the simply supported beam, the frequency ratio is $\beta=(\bar{\omega} / \omega)$, the loading frequency of the moving load crossing the bridge is $\bar{\omega}=(\pi V / L), \xi$ is the damping ratio, $\omega_{D}=\omega \sqrt{1-\xi^{2}}$ is the damped vibration frequency, and $1 /\left(\left(1-\beta^{2}\right)^{2}+(2 \xi \beta)^{2}\right)$ is the dynamic amplification factor of the simple supported beam. The first term is the transient response of the simple supported beam, and the second term is the steady-state response of the simple supported beam. The acceleration response formula can be derived from the displacement response formula and will not be listed here.

2.2. The Moving Mass Model. In actual engineering, the mass of the train is real, and as the mass ratio of the vehicle to the bridge increases, the inertial force generated by the dynamic action of the vehicle at the same speed is greater, so the vehicle is simplified to the moving mass model. As shown in Figure 2, it is assumed that the moving mass is not separated from the simple supported beam during the movement.

If the mass $M_{i j}$ passes through the bridge at a uniform speed $V$, the load acting on the beam is the sum of the mass's gravity $P_{G i j}=M_{i j} g$, and the mass's inertial force $P_{i j}=M_{i j} \mathrm{~d}^{2} y(x, t) / \mathrm{d} t^{2}$, and

$$
\frac{\mathrm{d}^{2} y}{\mathrm{~d} t^{2}}=\frac{\mathrm{d}^{2} y(x, t)}{\mathrm{d} t^{2}}+2 \frac{\partial^{2} y(x, t)}{\partial x \partial t} V+\frac{\partial^{2} y(x, t)}{\partial x^{2}} V^{2} .
$$

In the above formula, the first term is the vertical acceleration of the bridge; the second and third terms are, respectively, related to the vertical velocity change rate of the bridge and the curvature generated by the bridge. The values of these two items are small and negligible. Then, the bridge dynamic balance equation is

$$
E I \frac{\partial^{4} y(x, t)}{\partial x^{4}}+\bar{m} \frac{\partial^{2} y(x, t)}{\partial t^{2}}+c \frac{\partial y(x, t)}{\partial t}=\delta(x-V t) M_{i j}\left(g-\frac{\partial^{2} y(x, t)}{\partial t^{2}}\right) .
$$




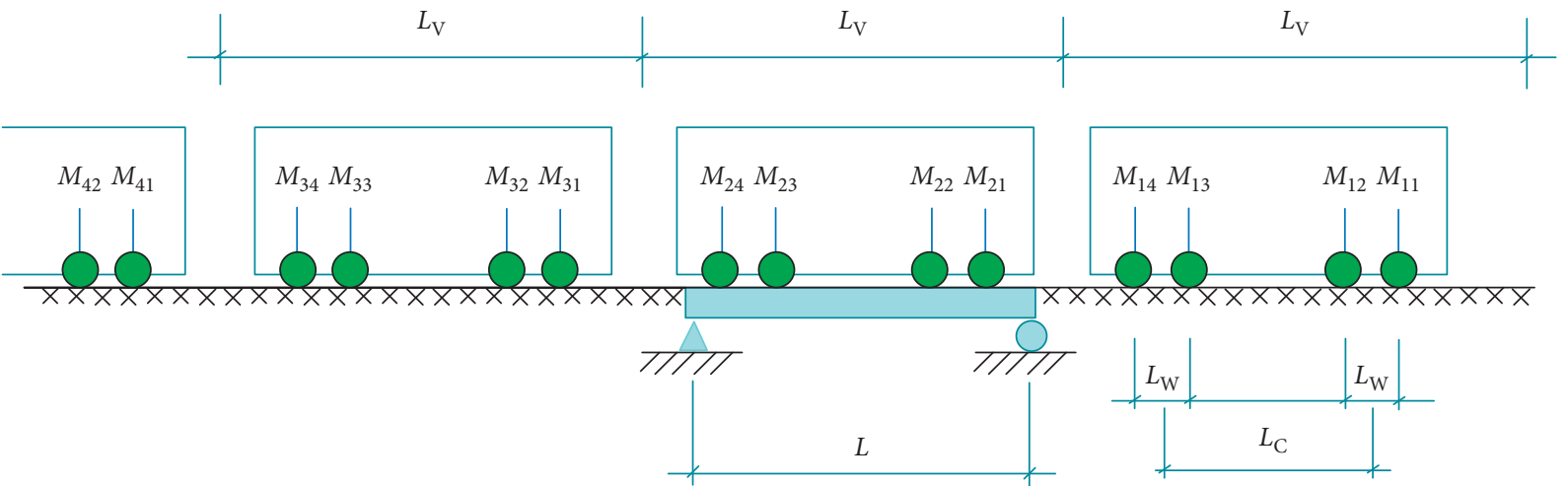

Figure 2: The moving mass model.

Use the mode decomposition method to solve, and take into account the orthogonal characteristics of the mode, and suppose $\phi_{n}(x)=\sin (n \pi x / L)$, and $x=V t$, and get

$$
\left[\ddot{q}_{n}(t)+\frac{2 M_{1}}{\bar{m} L} \sum_{i=1}^{\infty} \ddot{q}_{i}(t) \sin \frac{i \pi V t}{L} \sin \frac{n \pi V t}{L}\right]+2 \xi_{n} w_{n} \dot{q}_{n}(t)+\omega_{n}^{2} q_{n}(t)=\frac{2}{\bar{m} L} M_{i j} g \sin \frac{n \pi V t}{L} .
$$

Then, the equation of motion matrix expression of the simply supported beam is

$$
M\{\ddot{q}\}+C\{\dot{q}\}+K\{q\}=F .
$$

The specific content of each matrix in the formula can be found in literature [28]. The analytical solution of a simple supported beam under moving mass, although the modal decomposition method cannot be used to completely decouple the equations, but the original structural equation set with the order of $N$ reduction can be selected, and the stepwise integration method can be used to solve it.

2.3. The Spring-Damping-Mass Model. In order to further consider the springs and damping devices between the trains and further establish a vehicle-bridge model closer to the actual, the model is shown in Figure 3.

The moving load on the simple supported beam consists of the moving wheel mass $M_{1}$, the mass on the spring $M_{2}$, the damper $c_{1}$, and the spring $k_{1}$, and it is assumed that the mass $M_{1}$ does not separate from the simply supported beam body during the movement [28].
The force acting on the sprung mass $M_{2}$ includes the inertial force $P_{12}=M_{2} \ddot{Z}(t)$, the elastic force generated by the spring $P_{S}=\left.k_{1}[y(x, t)-Z(t)]\right|_{x=V t}$, and the damping force generated by the damper $P_{D}=c_{1}$ $\left.[\mathrm{d} y(x, t) / \mathrm{dt}-\dot{Z}(t)]\right|_{x=V t}$.

From the force balance on $M_{2}$ in the figure, the balance equation of $M_{2}$ can be obtained as

$$
\begin{aligned}
& M_{2} \ddot{Z}(t)+k_{1}\left[Z(t)-\left.y(x, t)\right|_{x=V t}\right] \\
& +c_{1}\left[\dot{Z}(t)-\left.\frac{\partial y(x, t)}{\mathrm{d} t}\right|_{x=V t}\right]=0 .
\end{aligned}
$$

Then, the force on the simple supported beam is the gravity $P_{G}=\left(M_{1}+M_{2}\right) g$ generated by the mass $M_{1}$ and $M_{2}$, and the inertial force of the mass $M_{1}$ is $P_{I}=M_{1} \cdot \mathrm{d}^{2} y(x, t) /\left.\mathrm{d} t^{2}\right|_{x=V t}$, the elastic force generated by the spring $P_{s}^{\prime}=\left.k_{1}[Z(t)-y(x, t)]\right|_{x=V t}$, and the damping force generated by the damper is $P_{D}^{\prime}=\left.c_{1}[\dot{Z}(t)-\mathrm{d} y(x, t) / \mathrm{d} t]\right|_{x=V t}$.

The dynamic balance equation of a simply supported beam is

$$
\begin{aligned}
& E I \frac{\partial^{4} y(x, t)}{\partial x^{4}}+\bar{m} \frac{\partial^{2} y(x, t)}{\partial t^{2}}+c \frac{\partial y(x, t)}{\partial t} \\
& =\delta(x-V t)\left[\left(M_{1}+M_{2}\right) g-M_{1} \cdot \frac{\partial^{2} y(x, t)}{\partial t^{2}}+k_{1}[Z(t)-y(x, t)]+c_{1}\left[\dot{Z}(t)-\frac{\partial y(x, t)}{\partial t}\right] .\right.
\end{aligned}
$$



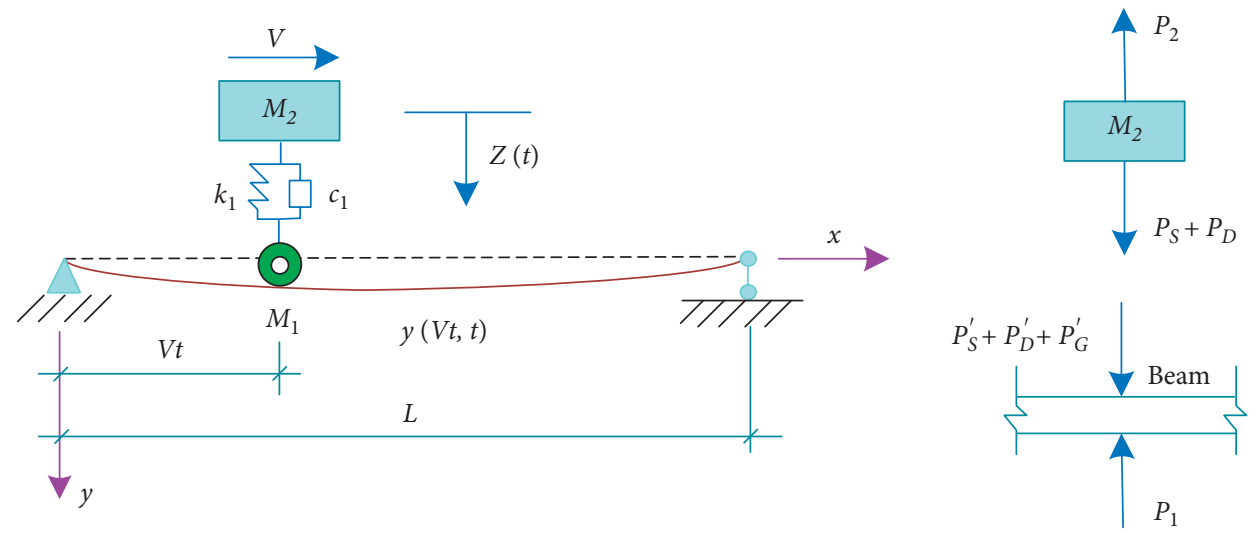

FIGURE 3: The spring-damping-mass model.

When solving by the mode decomposition method, in the case of a simple supported beam of equal cross section, set $\phi_{n}(x)=\sin (n \pi x / L)$, and $x=V t$, then

$$
\begin{aligned}
{\left[\ddot{q}_{n}(t)\right.} & \left.+\left(\frac{2 M_{1}}{\bar{m} L}\right) \sum_{i=1}^{\infty} \ddot{q}_{i}(t) \sin \frac{i \pi V t}{L} \sin \frac{n \pi V t}{L}\right]+\left[2 \xi_{n} \dot{q}_{n}(t)+\left(\frac{2 c_{1}}{\bar{m} L}\right) \sum_{i=1}^{\infty} \dot{q}_{i}(t) \sin \frac{i \pi V t}{L} \sin \frac{n \pi V t}{L}\right] \\
& +\left[\omega_{n}^{2} q_{n}(t)+\frac{2 k_{1}}{\bar{m} L} \sum_{\infty}^{\infty}\left[q_{i}(t) \sin \frac{i \pi V t}{L} \sin \frac{n \pi V t}{L}\right]-\left(\frac{2}{\bar{m} L}\right)\left[k_{1} Z(t)+c_{1} \dot{Z}(t)\right] \sin \frac{n \pi V t}{L}=\frac{2}{\bar{m} L}\left(M_{1}+M_{2}\right) g \sin \frac{n \pi V t}{L} .\right.
\end{aligned}
$$

According to the mass $M_{2}$ motion equation, the above equation can be sorted into

$$
\begin{aligned}
& M_{2} \dot{Z}(t)+c_{1} \dot{Z}(t)+k_{1} Z(t)-c_{1} \sum_{i=1}^{\infty} \dot{q}_{i}(t) \sin \frac{i \pi V t}{L} \\
& -k_{1} \sum_{i=1}^{\infty} q_{i}(t) \sin \frac{i \pi V t}{L}=0 .
\end{aligned}
$$

Combine equation (10) with equation (11) to obtain the dynamic balance equations of the simple supported beam. Therefore, in order to simplify the calculation, take $N$ terms for analysis; then, the expression of the $N+1$ order matrix of the dynamic motion equation of the simply supported beam is

$$
M\{\ddot{X}\}+C\{\dot{X}\}+K\{X\}=\{F\} .
$$

For each matrix parameter in the formula, see [28]. It can be seen that, in the analytical solution of a simply supported beam under the action of a moving wheel and a sprung mass model, the dynamic equation cannot be completely decoupled by the mode superposition method, and the equation can be calculated simply by reducing the order. And, the mass, stiffness, and damping matrix are also changing, so this time-varying differential equation system can be solved by stepwise integration.
2.4. The VBI Model. In this model, the vehicle considers $1 \mathrm{car}$ body, 2 bogies, and 4 wheelsets. The degrees of freedom for each car body and each bogie are $Z$ and $R_{y}$ directions, and the degree of freedom of each wheelset of analysis is the $Z$ direction. Therefore, each vehicle unit needs to calculate 10 degrees of freedom. The car is connected to the front and rear bogies through springs and damper bodies, and the bogies are connected to each corresponding wheelset through springs and dampers. The vehicle structure is shown in Figure 4 [28].

The wheel-rail relationship satisfies the close adhesion assumption, that is, the contact point between the upper wheelset of the train and the track is always close vertically. Considering the vehicle and the bridge separately, the vibration equation is as follows.

Dynamic motion equation of the vehicle subsystem:

$$
M_{V} \ddot{X}_{V}+C_{V} \dot{X}_{V}+K_{V} X_{V}=F_{V} .
$$

The dynamic equation of the bridge subsystem is

$$
M_{B} \ddot{X}_{B}+C_{B} \dot{X}_{B}+K_{B} X_{B}=F_{B} .
$$

Vehicles are programmed by means of programming. The bridge is modeled by the finite element based on the section characteristics in the previous section, and the whole process iteration method is used to calculate the dynamic response between vehicles and bridges. 


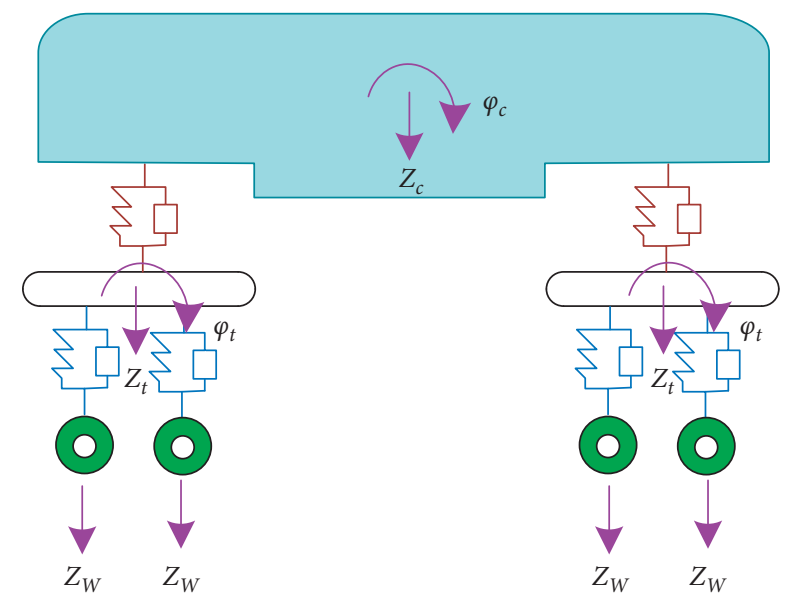

FIgURE 4: The vehicle structure.

2.5. Model Comparison Analysis. Among the above four models, due to different degrees of simplification, there are different vibration systems. The main differences between the four models are shown in Table 1.

\section{Comparison and Analysis of Simplified Calculation Methods for Vehicle- Bridge Coupling}

The four different methods in Section 2 are applied to analyze the vehicle-bridge coupling problem, and the vertical dynamic response of the simple supported beams acting on the above four calculation models is analyzed and compared by changing the vehicle-bridge coupling model parameters such as train speed and vehicle-bridge mass ratio. And, through the analysis and comparison of four vehicle-bridge coupling models, a calculation method with high efficiency and good accuracy is selected.

3.1. Model Parameter Selection. Taking the $32 \mathrm{~m}$ simple supported beam commonly used in railway bridges in China as the research object, the cross section is a typical single-box single-cell equal-height box girder. The top width of the beam box girder is $12 \mathrm{~m}$, the height is $3.05 \mathrm{~m}$, the bottom width of the box girder is $5.5 \mathrm{~m}$, the concrete is C55, the elastic modulus $3.55 \times 10^{10} \mathrm{~Pa}$, bending moment of inertia $I=11.092 \mathrm{~m}^{4}$, vertical first-order frequency is $4.89 \mathrm{~Hz}$, Poisson's ratio is 0.2 , and damping ratio is $2 \%$.

The vehicle uses $\mathrm{CRH} 3$, and its main parameters are shown in Table 2

3.2. Simplified Model Comparison Analysis. In order to analyze the effect of different size of bridge elements on the calculation results, the bridge elements are divided into six analytical cases: $0.1 \mathrm{~m}, 0.5 \mathrm{~m}, 1 \mathrm{~m}, 2 \mathrm{~m}, 4 \mathrm{~m}$, and $8 \mathrm{~m}$. Based on the parameters in the previous section, the maximum displacement of the bridge midspan under the moving load model is calculated, as shown in Figure 5.
The calculation result shows that the smaller the size of the bridge element is, the more accurate the result is. When the size is too large, the result is wrong. As shown in Figure 5, when the size of the bridge element is $4 \mathrm{~m}$, the result is a larger error in some speeds. When it reaches $8 \mathrm{~m}$, the error is even greater. Considering the calculation efficiency and the accuracy of the calculation results, in the following calculations, the size of the bridge element is $1 \mathrm{~m}$.

For the moving load model, comparing theoretical formula equation (3) with the results of the finite element method, the bridge midspan displacement at speeds from $50 \mathrm{~km} / \mathrm{h}$ to $350 \mathrm{~km} / \mathrm{h}$ and the bridge midspan displacement time history curves at speeds of $200 \mathrm{~km} / \mathrm{h}$ and $300 \mathrm{~km} / \mathrm{h}$ are calculated, respectively, as shown in Figures 6 and 7. It can be seen that they meet well. Therefore, it can also be proved that it is reasonable to use the same method to calculate the moving mass and the result of the moving vehicle model.

Based on the abovementioned vehicle-bridge coupling model, the dynamic response of the four models when the train passes through the bridge at a speed of $50 \mathrm{~km} / \mathrm{h}$ to $500 \mathrm{~km} / \mathrm{h}$ is calculated, respectively, as shown in Figures 8 and 9.

It can be seen from Figures 8 and 9 that the response trend of the bridge midspan displacement and acceleration of the four models at different speed levels are roughly the same. When the speed is less than $500 \mathrm{~km} / \mathrm{h}$, the dynamic response of the bridge basically satisfies the intensive moving mass model $>$ spring-damping-mass model $>$ VBI model $>$ moving load model among the four models. The analysis shows that, in the moving load model, the train is simplified into moving loads, and the inertial force generated by the mass of the train during the running process is ignored, so its value is the smallest. And, because the moving mass model does not consider the energy dissipation effect of the train's own stiffness and damping compared with the other two models, its value is the largest. Compared with the springdamping-mass model, a more complete stiffness and damping system is considered in the VBI model, and its energy consumption is more obvious, which makes the bridge response slightly smaller than that of the springdamping-mass model.

And, when the speed is $460 \mathrm{~km} / \mathrm{h}$, there is a peak value, and a small peak value also appears at the speed of $150 \mathrm{~km} / \mathrm{h}$. The dynamic response of the four models at a speed of $460 \mathrm{~km} / \mathrm{h}$ is shown in Figures 10 and 11 . It can be observed from the figure that the dynamic response of the bridge at this speed gradually increases with the continuous loading of the train, and there is an obvious resonance phenomenon, and it conforms to the resonance critical speed calculated by formula (15) in the literature [28]. The calculation result is shown in Table 3:

$$
V_{\mathrm{res}}=\frac{f_{n} \times L_{\mathrm{V}}}{i}
$$

Taking the VBI model as a reference, we named the difference between the bridge response obtained by the other three models and the space multi-degree-of-freedom 
TABLE 1: Simplified comparison of different models.

\begin{tabular}{|c|c|c|c|c|c|}
\hline Model & Mass & Gravity & Inertial force & Stiffness & Damping \\
\hline The moving load model & - & $P_{G}=M_{1} g$ & - & - & - \\
\hline The moving mass model & $M_{1}$ & $P_{G}=M_{1} g$ & $P_{1}=M_{1} \mathrm{~d}^{2} y_{.}(x, t) / \mathrm{d} t^{2}$ & - & - \\
\hline $\begin{array}{l}\text { The spring-damping-mass } \\
\text { model }\end{array}$ & $M_{1}+M_{2}$ & $P_{G}=\left(M_{1}+M_{2}\right) g$ & $\begin{array}{c}P_{12}=M_{2} \ddot{Z}(t) \text { and } \\
P_{I}=M_{1} \cdot \mathrm{d}^{2} y(x, t) /\left.\mathrm{d} t^{2}\right|_{x=V t}\end{array}$ & $K_{1}$ & $C_{1}$ \\
\hline The VBI model & $\begin{array}{l}\text { Complete } \\
\text { wheelset, } \\
\text { bogie, and } \\
\text { body mass }\end{array}$ & $\begin{array}{l}\text { Gravity generated by the } \\
\text { complete wheelset, } \\
\text { bogie, and car body mass }\end{array}$ & $\begin{array}{c}\text { Inertial force generated by } \\
\text { wheelsets, bogies, and car } \\
\text { bodies }\end{array}$ & $\begin{array}{l}\text { Primary } \\
\text { spring and } \\
\text { secondary } \\
\text { spring }\end{array}$ & $\begin{array}{c}\text { Primary } \\
\text { damping and } \\
\text { secondary } \\
\text { damping }\end{array}$ \\
\hline
\end{tabular}

complex model divided by the bridge response obtained by the complex model as the deviation rate.

Taking the VBI model as a reference, we named the difference between the bridge response obtained by the other three models and VBI model divided by the bridge response obtained by the VBI model as the deviation rate of the dynamic coefficient, such as formula (16). The maximum deviation rates of the three models at different speeds are shown in Figures 12 and 13:

$$
D=\frac{D_{i}-D_{\mathrm{VBI}}}{D_{\mathrm{VBI}}},
$$

where $D$ represents the deviation rate of the dynamic coefficient, $D_{i}$ represents the bridge dynamic coefficient under the model of moving load, moving mass, and springdamping mass, and $D_{\mathrm{VBI}}$ represents the bridge dynamic coefficient under the VBI model.

The full text uses 5\% deviation rate as the evaluation index. When the deviation rate is less than $5 \%$, it means that the model meets the calculation accuracy requirements, and when the deviation rate is greater than $5 \%$, it means that the model cannot meet the calculation accuracy requirements of vehicle-bridge dynamics.

The analysis shows that when the deviation rate value is greater than 0 , it means that the calculation result of the model is larger than the calculation result of the VBI model, that is, this model can better contain the response of the real vehicle-bridge system, and the calculation is more reliable. Conversely, when the difference is less than 0 , the model calculation result is smaller than the real result. When used as a bridge response model, it is too conservative and cannot be used to evaluate the dynamic performance of the bridge. It can be seen from Figure 12 that, in the calculation results of the moving load model, the deviation rate is less than 0 , and the absolute value of the deviation rate near the resonance speed exceeds 5\%. Therefore, this model needs to be processed before it can be used in the vehicle-bridge coupling calculation. In the calculation results of the moving mass model and the spring-damping-mass model, the deviation rate is between $5 \%$ and $15 \%$ only near the resonance speed, and the deviation rate at the other speeds meets the
TABLE 2: Vehicle parameters.

\begin{tabular}{lc}
\hline Main parameters & Value \\
\hline Distance of wheel sets $(\mathrm{m})$ & 2.5 \\
Distance of bogies $(\mathrm{m})$ & 18 \\
Length of each car $(\mathrm{m})$ & 26.3 \\
Wheel set mass $(\mathrm{kg})$ & 2200 \\
Bogie mass $(\mathrm{kg})$ & 3400 \\
Bogie $Z$-inertia $\left(\mathrm{kg} \cdot \mathrm{m}^{2}\right)$ & 6800 \\
Car body mass $(\mathrm{kg})$ & 42400 \\
Car body Z-inertia $\left(\mathrm{kg} \cdot \mathrm{m}^{2}\right)$ & 2740000 \\
Primary suspension $z$-damp/side $(\mathrm{kN}-\mathrm{s} / \mathrm{m})$ & 40 \\
Secondary suspension $z$-damp/side $(\mathrm{kN}-\mathrm{s} / \mathrm{m})$ & 45 \\
Primary suspension $z$-spring/side $(\mathrm{MN} / \mathrm{m})$ & 1.04 \\
Secondary suspension $z$-spring/side $(\mathrm{MN} / \mathrm{m})$ & 0.4 \\
\hline
\end{tabular}

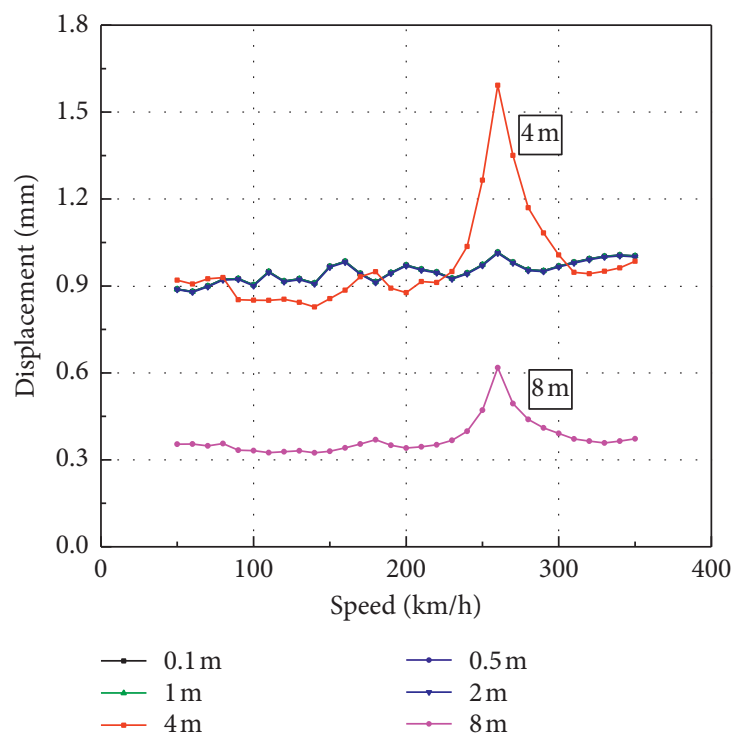

FIgURE 5: The maximum midspan displacement of the bridge under different sizes of the bridge element.

limit of less than $5 \%$ as a whole. It shows that, in addition to the resonance speed, these two models can well reflect the displacement of the bridge in the real vehicle-bridge coupled 


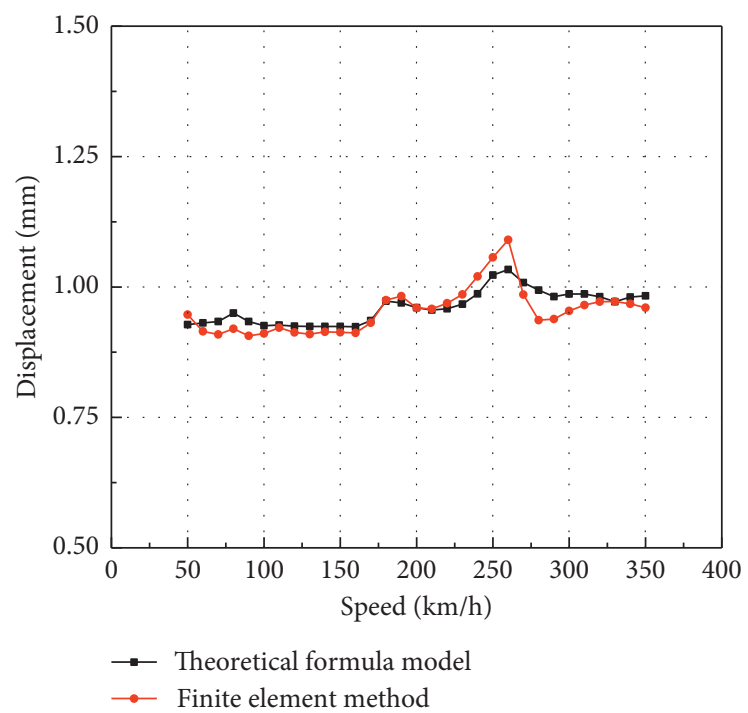

FIgURE 6: The maximum displacement of the bridge midspan under the two models at different speeds.
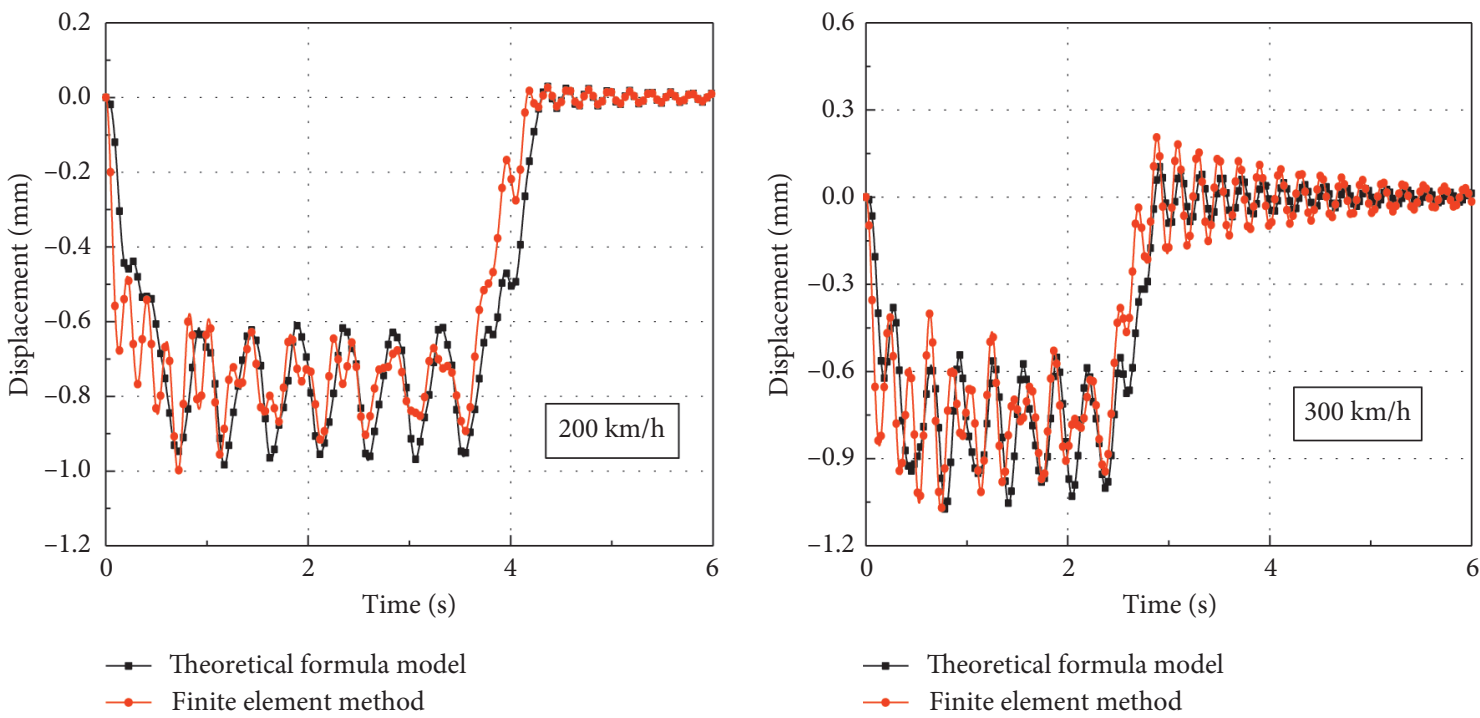

Figure 7: The displacement of the bridge midspan under the two models at a speed of $200 \mathrm{~km} / \mathrm{h}$ and $300 \mathrm{~km} / \mathrm{h}$.

vibration, which can be used to guide the design of the bridge.

It can be seen from Figure 13 that the acceleration deviation rates of the three models are relatively large, so none of the three calculation models can reflect the more accurate bridge vibration acceleration.

\subsection{Analysis of Results under Different Vehicle-Bridge Mass} Ratios. Based on the parameters of the vehicle and simple supported beam in the above section, the mass ratio of the single carriage to the one-span simple supported beam is about $1 / 21$. Therefore, the working conditions shown in
Table 4 are set to study the applicability of several models under different vehicles to bridge mass ratios. The vehicle mass is about $26.7 \mathrm{t} \sim 267 \mathrm{t}$.

Under different mass ratio conditions, the midspan deviation rate of the dynamic coefficient of the three models in the speed range of $50 \mathrm{~km} / \mathrm{h} \sim 500 \mathrm{~km} / \mathrm{h}$ is shown in Figures 14-16. Figure 17 is the calculation result of the midspan displacement of the spatial VBI model.

It can be seen from Figure 17 that, with the increase of the vehicle bridge mass ratio, the load acting on the bridge increases, and the midspan displacement of the bridge increases. According to Figure 14, the moving load model has the same rule as Section 3.2 under different mass ratios, and 


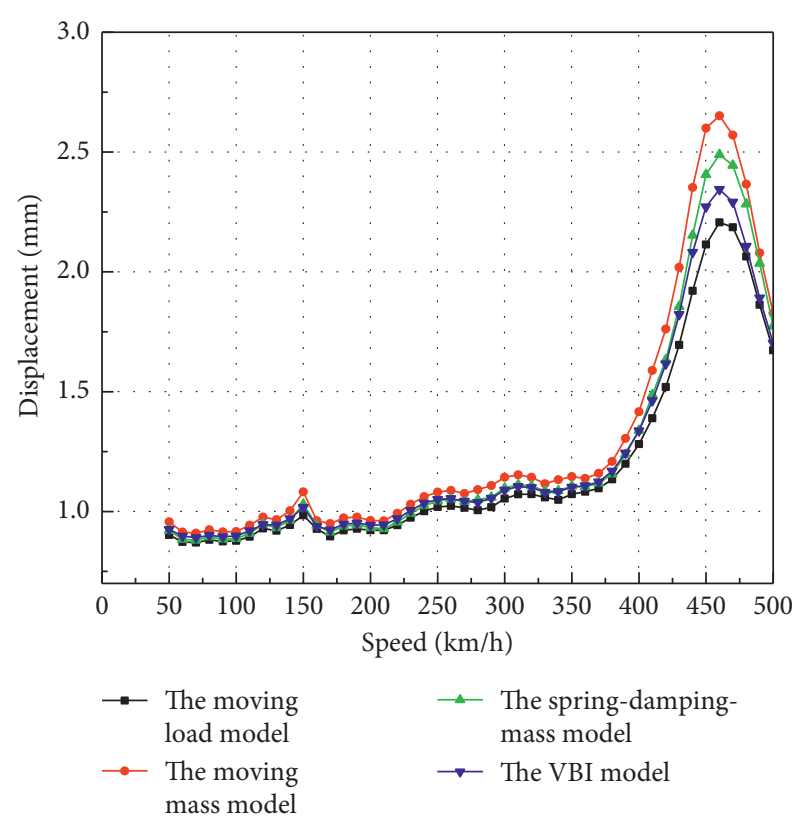

FIgURE 8: The maximum displacement of the bridge under the four models at different speeds.

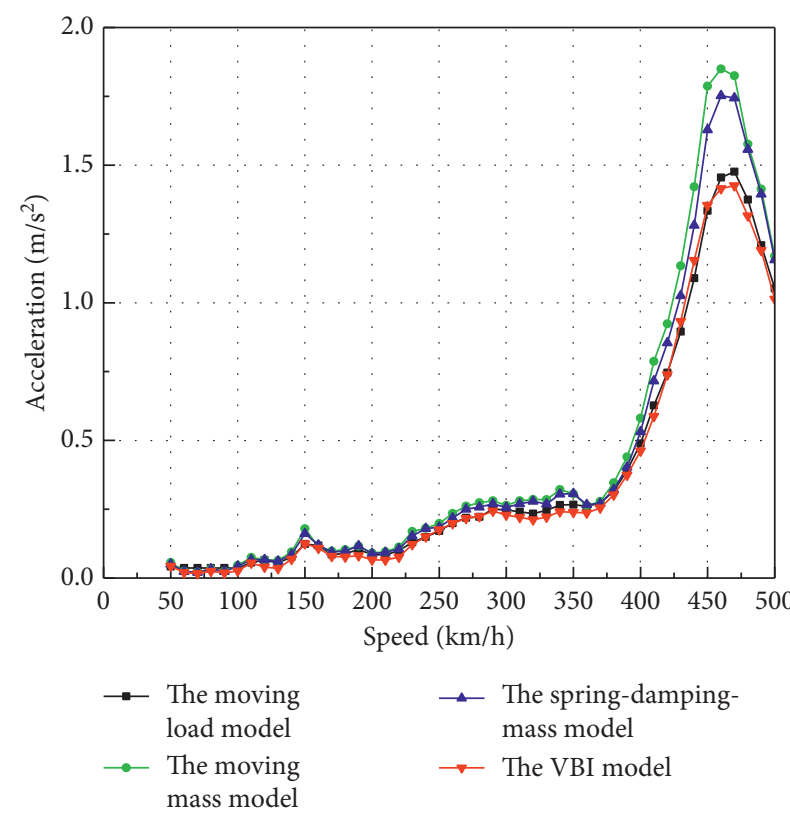

Figure 9: The maximum acceleration of the bridge under the four models at different speeds.

the absolute deviation rate is more than $5 \%$ within the speed range of $410 \mathrm{~km} / \mathrm{h} \sim 470 \mathrm{~km} / \mathrm{h}$ (that is, $90 \% \sim 105 \%$ of resonance speed). In Figure 16, in the calculation results of the moving mass model, the increase of the mass ratio makes the deviation rate increase, and the deviation rate is more than $5 \%$ in the speed range of $390 \mathrm{~km} / \mathrm{h} \sim 500 \mathrm{~km} / \mathrm{h}$ (that is, $84.7 \% \sim 108.6 \%$ of the resonance speed). In other speeds, the moving mass model is in good agreement with the VBI model. In Figure 16, in the spring-damping-mass model, in

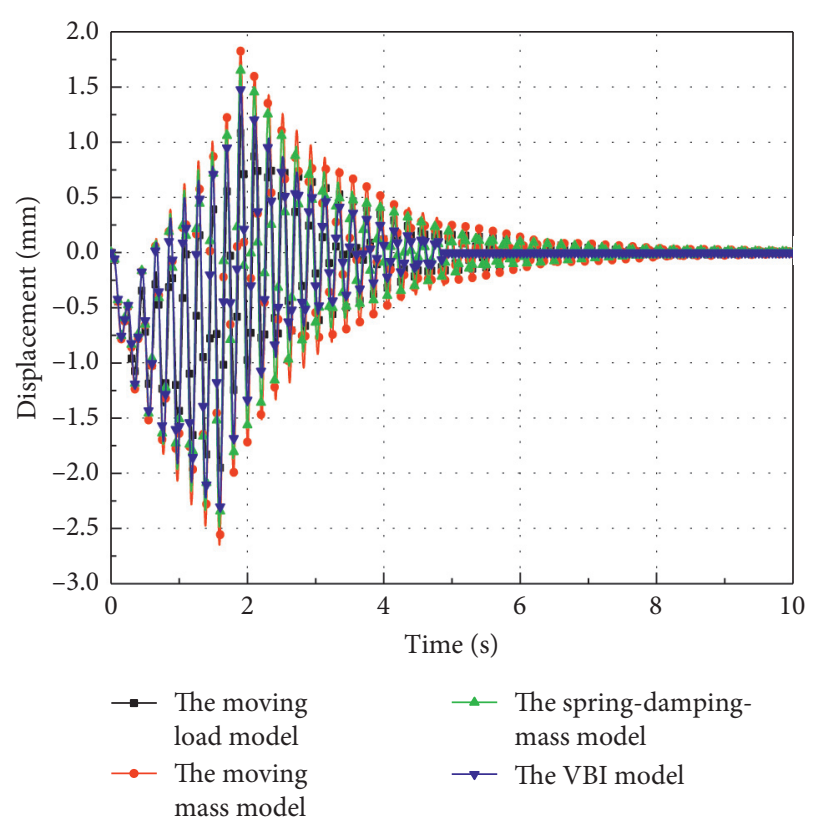

Figure 10: The maximum displacement of the bridge midspan under the four models at a speed of $460 \mathrm{~km} / \mathrm{h}$.

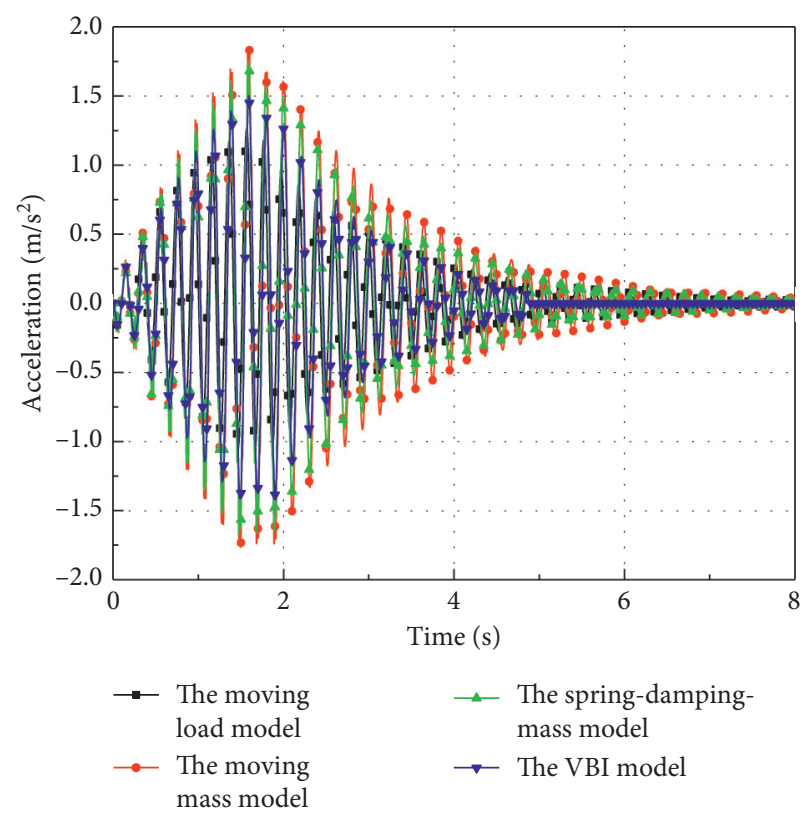

FIgURE 11: The maximum acceleration of the bridge midspan under the four models at a speed of $460 \mathrm{~km} / \mathrm{h}$.

TABLE 3: The results of resonance critical speed.

\begin{tabular}{lccccc}
\hline Number & 1 & 2 & 3 & 4 & 5 \\
\hline Speed $(\mathrm{km} / \mathrm{h})$ & 463.74 & 231.87 & 154.58 & 115.94 & 92.75 \\
\hline
\end{tabular}

the speed range of $430 \mathrm{~km} / \mathrm{h} \sim 500 \mathrm{~km} / \mathrm{h}$ (that is, $93 \% \sim 108.6 \%$ of the resonance speed), the deviation rate is more than $5 \%$. In other speeds, the spring-damping-mass model is in good agreement with the VBI model. 


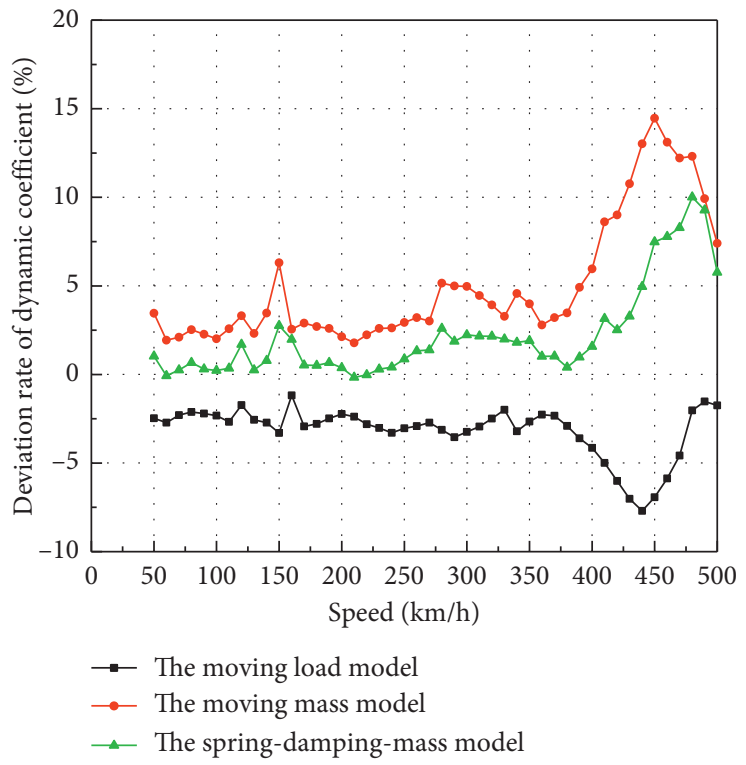

FIGURE 12: Deviation rate of the dynamic coefficient of the bridge midspan under different models.

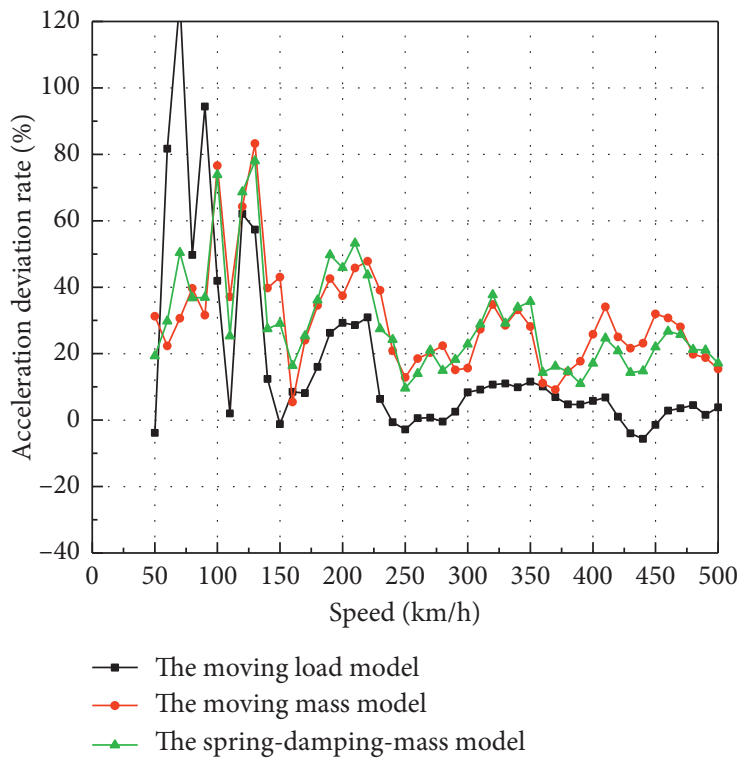

Figure 13: Deviation rate of acceleration of the bridge midspan under different models.

TABLE 4: Analysis working conditions of different vehicles and bridge mass ratios.

\begin{tabular}{|c|c|c|c|c|c|c|c|c|c|c|}
\hline Working condition & 1 & 2 & 3 & 4 & 5 & 6 & 7 & 8 & 9 & 10 \\
\hline Mass ratio of vehicle to bridge & $1 / 5$ & $1 / 10$ & $1 / 15$ & $1 / 20$ & $1 / 25$ & $1 / 30$ & $1 / 35$ & $1 / 40$ & $1 / 45$ & $1 / 50$ \\
\hline
\end{tabular}

Observing Figures 14-16, we can see that, under different vehicle-bridge mass ratios, the deviation rate between the results of the moving load model and the results of the VBI model is small, and it has good stability. However, the deviation rate of the moving mass model and the springdamping-mass model varies to different degrees with different working conditions, and the deviation rate is relatively poor under stable conditions.

Figure 18 shows the maximum deviation rate of the bridge midspan dynamic coefficient under the action of the moving load model after coefficient correction. Multiply the coefficient of 1.1 within the range of $90 \% \sim 105 \%$ of resonance 


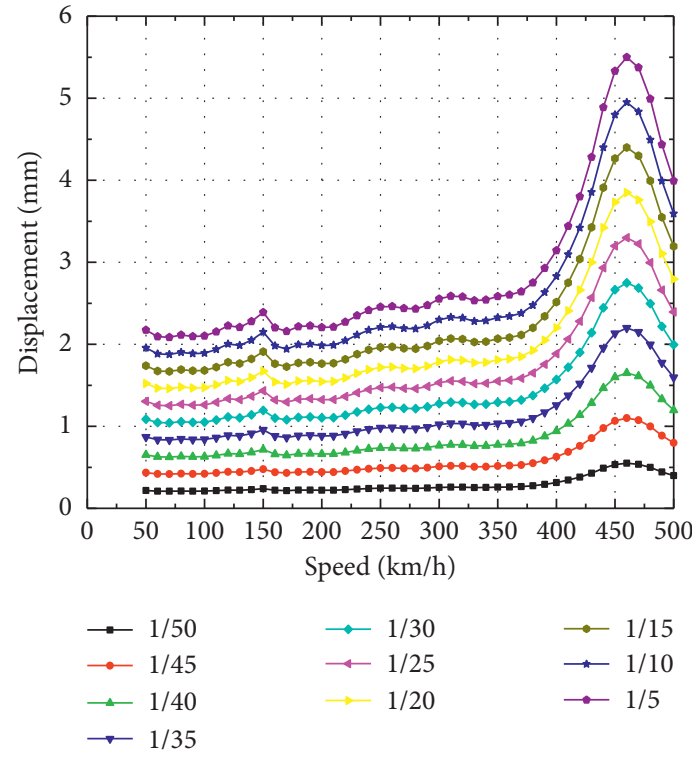

Figure 14: Dynamic coefficient deviation rate of the bridge under the moving load model.

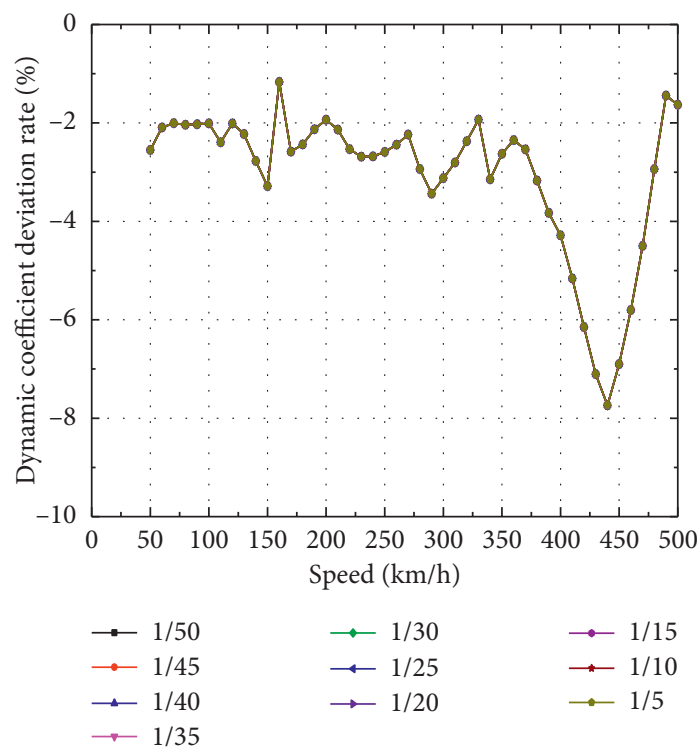

FIGURE 15: Dynamic coefficient deviation rate of the bridge under the moving mass model.

speed, and multiply the coefficient of 1.05 under other speeds so that the deviation rates are all positive, that is, the bridge dynamic coefficient results of the moving load model can envelope the results of VBI, and the deviation rate is less than $5 \%$.

3.4. Analysis of the Result of the Stiffness Change of a Series of Springs. In the calculation of the vehicle-bridge system, in order to study the influence of the primary spring stiffness

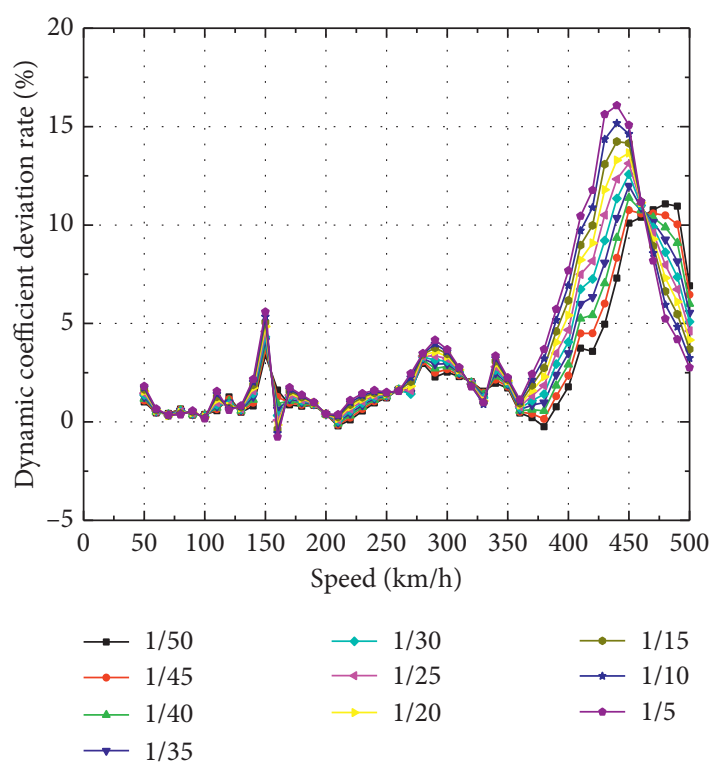

FIgURE 16: Dynamic coefficient deviation rate of the bridge under the spring-damping-mass model.

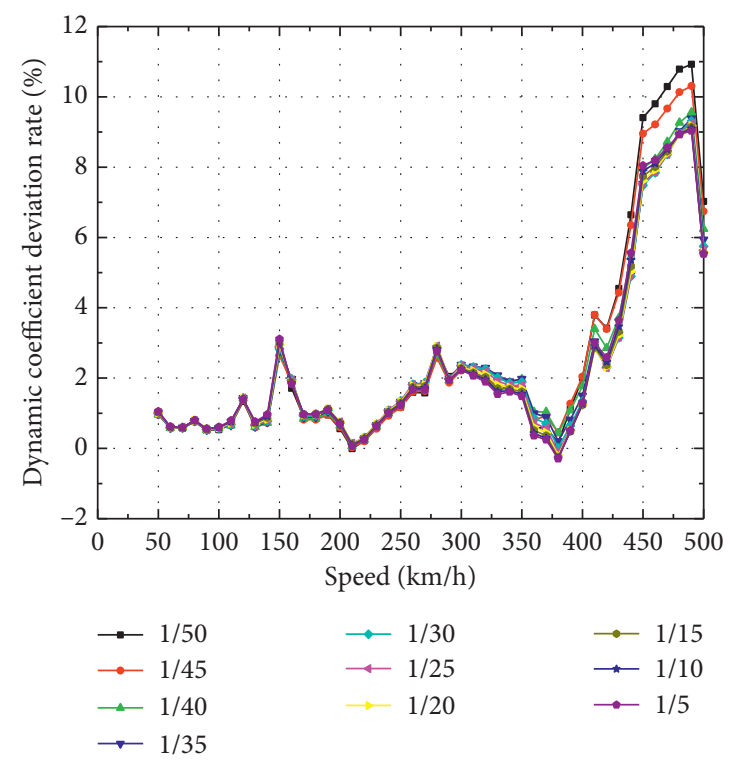

FIgURE 17: The maximum displacement of the bridge span of the VBI model.

on the coupled vibration of the vehicle bridge, the current primary spring stiffness of the vehicle is set to $k_{1}$, and the force of the unit displacement generated by the concentrated force in the bridge midspan is $k_{2}$; then, the stiffness ratio of the vehicle to bridge is $k_{1} / k_{2}$, and $k_{0}=k_{1} / k_{2}$. Now calculate the displacement deviation rate of the bridge midspan under the action of the spring-damping-mass model and the VBI model within the stiffness variation range of Table 5 , as shown in Figure 19. The value range of $k_{1}$ is $0.104 \sim 10.4 \mathrm{MN} / \mathrm{m}$. 


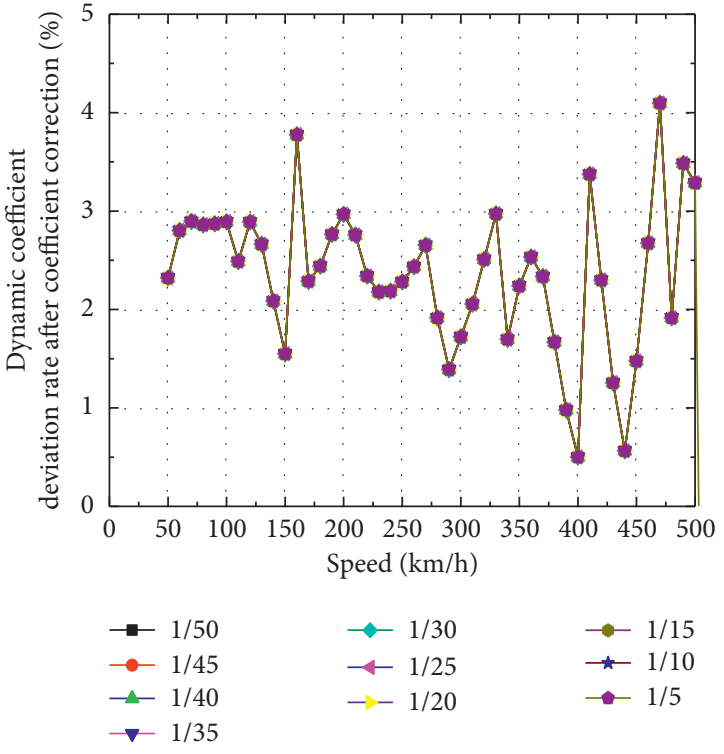

FIGURE 18: The maximum dynamic coefficient deviation rate of the bridge under the moving load model after the coefficient correction.

TABLE 5: Working conditions of the primary spring stiffness of the vehicle.

\begin{tabular}{lcccccc}
\hline Conditions & 1 & 2 & 3 & 4 & 5 & 6 \\
\hline Stiffness & $1 / 10 k_{0}$ & $1 / 8 k_{0}$ & $1 / 6 k_{0}$ & $1 / 4 k_{0}$ & $1 / 2 k_{0}$ & $1 k_{0}$ \\
Conditions & 7 & 8 & 9 & 10 & 11 & - \\
Stiffness & $2 k_{0}$ & $4 k_{0}$ & $6 k_{0}$ & $8 k_{0}$ & $10 k_{0}$ & - \\
\hline
\end{tabular}

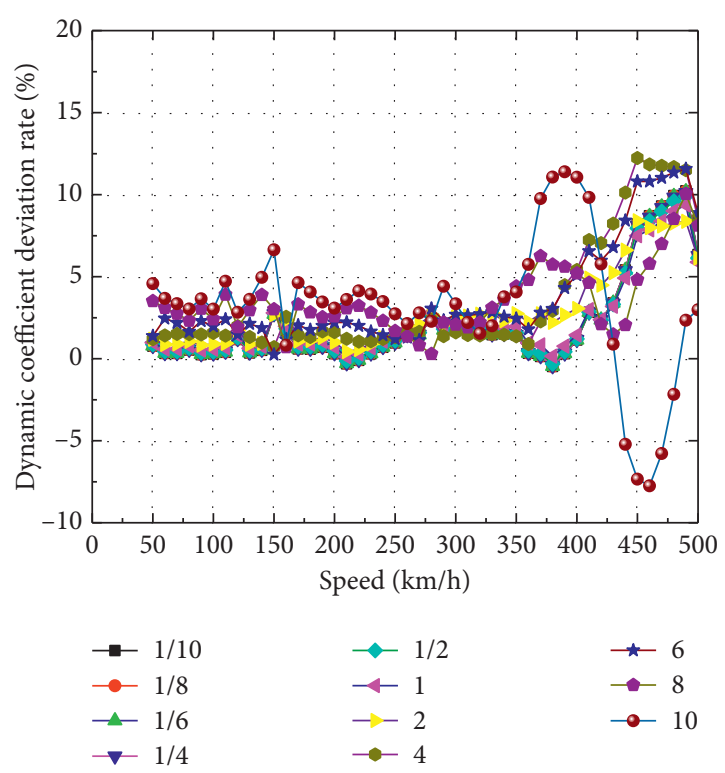

FIgURE 19: Dynamic coefficient deviation rate of the bridge under the spring-damping-mass model.
It can be seen from the analysis in Figure 19 that when the stiffness of the primary spring changes within a certain range, the deviation rate is greater than $5 \%$ within the speed range of $370 \mathrm{~km} / \mathrm{h} \sim 500 \mathrm{~km} / \mathrm{h}$ (that is, $80.4 \% \sim 119.6 \%$ of the resonance speed). At other speeds, the spring-dampingmass model is in good agreement with the VBI model.

\section{Conclusions}

Four different vehicle-bridge coupling calculation models are calculated. The speed range covers the range of $50 \mathrm{~km} /$ $\mathrm{h} \sim 500 \mathrm{~km} / \mathrm{h}$, and the change of the vehicle-bridge mass ratio and various primary spring stiffness also covers many types of vehicles.

(1) In the applicability analysis of the calculation model, the first three models can better reflect the dynamic coefficients of the bridge in the coupled vibration of the vehicle bridge and are used to guide the design of the bridge. However, the acceleration deviation rates of the three models are relatively large, so they cannot reflect the more accurate bridge vibration acceleration.

(2) The moving load model ignores the train mass. Compared with the other three models, the moving load model lacks the inertial force generated by the mass under the dynamic action, which makes the calculation results of the bridge midspan dynamic coefficient smaller and cannot cover all the calculation results of the VBI model, which makes the calculation results dangerous. Therefore, multiplying the range of $90 \% \sim 105 \%$ of its resonance speed by a coefficient of 1.1 and multiplying the remaining speeds by a coefficient of 1.05 to obtain a result consistent with the degree of freedom of space.

(3) In the model of the moving mass and springdamping-mass, except for the range of $80 \% \sim 120 \%$ of the first resonance speed, the deviation rate of bridge midspan displacement in the other speed ranges is less than 5\%, which is in good agreement with the model of VBI. However, in the case of different axle mass ratios, the deviation rate from the result of the VBI model has a relatively large change, and it cannot be solved by simply multiplying the coefficient.

(4) Considering that the moving load train model is relatively simple and efficient and has good stability with the results of the multi-degree-of-freedom spatial model under different working conditions, the moving load train model with coefficient correction is recommended as a simplified model of vehicle-bridge coupling vibration. 


\section{Data Availability}

All the raw data used to support the findings of this study are included within the article and from the corresponding author upon request.

\section{Conflicts of Interest}

The authors declare that they have no conflicts of interest.

\section{Acknowledgments}

The work was financially supported by the Fundamental Research Funds for the Central Universities of China (2020YJS132).

\section{References}

[1] N. Xue, Research on Effect of China Railway Speed-Up, Beijing Jiaotong University, Beijing, China, 2010, in Chinese.

[2] C. Tian, "China's railway train speed, density and weight in developing," China Railways Science, vol. 41, no. 4, pp. 127135, 2020, in Chinese.

[3] J.-G. Zhou and G.-H. Wang, "Coupling vibration research on vehicle-bridge system," IOP Conference Series: Earth and Environmental Science, vol. 267, no. 4, Article ID 42104, 2019.

[4] Y. Li, S. Dong, Y. Bao, K. Chen, and S. Qiang, "Impact coefficient analysis of long-span railway cable-stayed bridge based on coupled vehicle-bridge vibration," Shock and Vibration, vol. 2015, Article ID 641731, 9 pages, 2015.

[5] H. Gou, L. Yang, Z. Mo, W. Guo, X. Shi, and Y. Bao, "Effect of long-term bridge deformations on safe operation of highspeed railway and vibration of vehicle-bridge coupled system," International Journal of Structural Stability and Dynamics, vol. 19, no. 7, pp. 645-660, 2019.

[6] S. P. Timoshenko, "On the forced vibration of bridges," Philosophical Magazine Series 6, vol. 43, no. 257, pp. 1018-1019, 1922.

[7] C. E. Inglis, A Mathematical Treatise on Vibrations in Railway Bridges, Cambridge University Press, Cambridge, UK, 1934.

[8] V. Kolousek, Dynamics in Engineering Structures, Butterworths, London, UK, 1937.

[9] J. Li and H. Zhang, "Moving load spectrum for analyzing the extreme response of bridge free vibration," Shock and Vibration, vol. 2020, Article ID 9431620, 13 pages, 2020.

[10] Y.-B. Yang, J.-D. Yau, and L.-C. Hsu, "Vibration of simple beams due to trains moving at high speeds," Engineering Structures, vol. 19, no. 11, pp. 936-944, 1997.

[11] T. R. Hamada, "Dynamic analysis of a beam under a moving force: a double Laplace transform solution," Journal of Sound and Vibration, vol. 74, no. 2, pp. 221-233, 1981.

[12] H. Gao and B. Yang, "Dynamic response of a beam structure excited by sequentially moving rigid bodies," International Journal of Structural Stability and Dynamics, vol. 20, no. 8, Article ID 2050093, 2020.
[13] A. T. Ju, S. Y. Qu, X. M. Hou, and J. T. Wang, "Influence of hoop coefficient on dynamic response of railway bridge protective frame under impact load," Advanced Materials Research, vol. 291-294, pp. 1321-1326, 2011.

[14] D. Huang, L. Hong, and C. Liu, "A. Computational technique for free vibration response of a 2-DOF parametric system," International Journal of Structural Stability and Dynamics, vol. 19, no. 12, Article ID 1950152, 2019.

[15] D. Huang, "Forced response approach of a parametric vibration with a trigonometric series," Mechanical Systems and Signal Processing, vol. 52-53, no. 53, pp. 495-505, 2015.

[16] S. Demirtas, H. Ozturk, and M. Sabuncu, "Dynamic response of multi-bay frames subjected to successive moving forces," International Journal of Structural Stability and Dynamics, vol. 19, no. 1, Article ID 1950042, 2018.

[17] S. Bashmal, "Determination of critical and cancellation speeds of euler-Bernoulli beam subject to a continuously moving load," International Journal of Structural Stability and Dynamics, vol. 19, no. 1, Article ID 1050030, 2018.

[18] UIC CODE 776-2, "Design requirements for rail-bridges based on interaction phenomena between train track and bridge," International Union of Railways, Paris, France, 2009.

[19] Y.-B. Yang and J.-D. Yau, "Vehicle-bridge interaction element for dynamic analysis," Journal of Structural Engineering, vol. 123, no. 11, pp. 1512-1518, 1997.

[20] Y. B Yang and J. D. Yau, "Vertical and pitching resonance of train cars moving over a series of simple beams," Journal of Sound \& Vibration, vol. 337, no. 1, pp. 134-149, 2015.

[21] A. Mamandi and M. H. Kargarnovin, "Nonlinear dynamic analysis of a Timoshenko beam resting on a viscoelastic foundation and traveled by a moving mass," Shock and Vibration, vol. 2014, Article ID 242090, 10 pages, 2014.

[22] G. Chen, L. Qian, and Q. Yin, "Dynamic analysis of a Timoshenko beam subjected to an accelerating mass using spectral element method," Shock and Vibration, vol. 2014, Article ID 768209, 12 pages, 2014.

[23] Y. Jun, Z. Jinqiu, Z. Ingmei, and P. Hu, "Analysis of dynamic stability of nonlinear suspension concerning slowly varying sprung mass," Shock and Vibration, vol. 2017, Article ID 5341929, 12 pages, 2017.

[24] S. H. Yin, "Vibration of a simple beam subjected to a moving sprung mass with initial velocity and constant acceleration," International Journal of Structural Stability \& Dynamics, vol. 16, no. 3, Article ID 1450109, 2016.

[25] G. Tan, W. Wang, Y. Cheng, H. Wei, Z. Wei, and H. Liu, "Dynamic response of a nonuniform Timoshenko beam with elastic supports, subjected to a moving spring-mass system," International Journal of Structural Stability and Dynamics, vol. 18, no. 5, Article ID 1850066, 2018.

[26] M. Gao, "Studies on train-track-bridge coupling vibration and train performance on high-speed railway bridges," China Railway Science, vol. 23, no. 2, pp. 134-138, 2002, in Chinese.

[27] Q. Zhang, M. Gao, L. Ma, Y. Xuan, and H. Li, "Train-bridge coupled vibration of Hutong Yangtze River bridge's approach bridge," Journal of Vibration and Shock, vol. 37, no. 7, pp. 132-138, 2018, in Chinese. 
[28] N. Zhang, W. Guo, and H. Xia, Coupling Vibrations of TrainBridge System in High-Speed Railway, Beijing Jiaotong University Press, Beijing, China, 2018, in Chinese.

[29] H. Xia and N. Zhang, "Dynamic analysis of railway bridge under high-speed trains," Computers \& Structures, vol. 83, no. 23-24, pp. 1891-1901, 2005.

[30] X. T. Du, H. Xia, and T. Zhang, "Numerical stability of iterative scheme in solving coupled vibration of a train-bridge system," Journal of Vibration and Shock, vol. 31, no. 22, pp. 62-65, 2012, in Chinese.

[31] N. Zhang and H. Xia, "A vehicle-bridge interaction dynamic system analysis method based on inter-system iteration," China Railway Science, vol. 34, no. 5, pp. 32-38, 2013.

[32] H. Li, H. Xia, N. Zhang, and X. Du, "Calculation method for dynamic stress of bridge based on vehicle-bridge coupled dynamic analysis," China Railway Science, vol. 36, no. 1, pp. 68-74, 2015, in Chinese. 